INTERNATIONAL DESIGN CONFERENCE - DESIGN 2018

https://doi.org/10.21278/idc.2018.0358

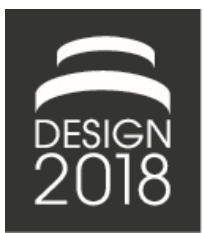

\title{
PRODUCT SERVICE SYSTEM DESIGN IN A SYSTEM OF SYSTEMS CONTEXT: A LITERATURE SURVEY
}

\author{
A. M. Hein, B. Poulain, M. Jankovic, Y. Chazal and S. Fakhfakh
}

\begin{abstract}
Product service systems (PSS) can be understood as an innovation / business strategy that includes a set of products and services that are embedded into an actor network. This paper presents the concept of PSS-System of Systems. We present how existing PSS and system of systems design approaches can be applied to PSS-SoS design.
\end{abstract}

Keywords: product development, product-service systems (PSS), systems engineering (SE), complex systems, cyber physical systems

\section{Introduction}

At its core, Product service systems (PSS) can be understood as a set of products and services (Goedkoop et al., 1999; Mont, 2002; A Tukker, 2004; Baines et al., 2007; Boehm and Thomas, 2013; Haase et al., 2017). In general, a product is a tangible good that takes part in an economic exchange, whereas a service is an intangible good taking part in an economic exchange (Lovelock and Gummesson, 2004). PSS are considered as a means to open up new market segments and/or to increase sustainability (Goedkoop et al., 1999).

More recently, complex PSS have been increasingly of interest, where collaboration plays an important role. An example is the Batteries for Buildings (B4B) system where batteries from electric vehicles are reused as a storage facility for providing energy management and renewables integration services (Chazal et al., 2017). This PSS is jointly developed and operated by Renault and Bouygues Energies \& Services and involves multiple systems. Another example is multi-modal transportation where distinct transportation providers jointly offer a transportation service. Such collaborative PSS commonly have some of the following characteristics:

- Multiple actors providing lower-level services that are combined into a higher-level service.

- Interoperability between systems becomes a key concern: Protocols, data exchange standards, etc.

- Societal concerns such as pollution reduction, quality of life, and job creation become crucial for getting approval from public stakeholders.

- Governance of the combined service and physical products becomes a key issue, e.g. one central actor has oversight vs. no single actor responsible for overall system.

These PSS seem to resemble what Maier (1996) calls "collaboratively integrated systems", which is for him a synonym for System of Systems (SoS) (Maier, 1996). According to Maier, a key characteristic of SoS is the operational and managerial independence of its constituent systems. In the following, we call such PSS "PSS-SoS". However, very few publications on PSS and on SoS explicitly deal with this 
relationship. We argue that exploring this relationship could help understanding these collaborative PSS and support the development of methods and tools for their design.

In this paper, we identify existing gaps in the PSS literature with respect to PSS-SoS design. First, PSS and SoS definitions from the literature are presented and their common and distinct characteristics identified. Next, a tentative definition for PSS-SoS is presented. Subsequently, various approaches for PSS and SoS design are assessed with respect to how far they can contribute to the design of PSS-SoS. Finally, research gaps and questions with respect to a future PSS-SoS design approach are formulated.

\section{PSS and SoS definitions and characteristics}

\subsection{PSS definitions and characteristics}

The first part of the current state-of-the-art is an endeavour to define PSS. Several publications provide overviews of PSS definitions from the literature (Arnold Tukker, 2004; Tukker and Tischner, 2006; Baines et al., 2007; Velamuri et al., 2011; Haase et al., 2017; Mahut et al., 2017). In essence, we conclude that most definitions consider PSS as either a business model / innovation strategy or as a combination of product(s) and service(s), depending on the emphasis on the business impact of PSS or its embodiment in the form of products and services. As an innovation strategy, PSS are subject to the bounded rationality of the actor network into which the PSS is embedded, which implies that PSS are subject to a continuous learning process (Whittington, 2001). This process is reflected in the coproduction with the customer and supporting infrastructure are important elements of PSS (Goedkoop et al., 1999; Mont, 2002; Morelli, 2006; Becker et al., 2010). Only one publication mentions system of systems in its definition Estrada et al. (2017) define PSS as "a system of systems consisting of a system product and a set of system services, which are jointly capable of fulfilling a specific customer demand". This hints at a research gap regarding PSS-SoS in the literature. Figure 1 shows PSS elements that form part of most definitions. A PSS is primarily a set of products and services, supported by an actor network and can be part of a specific business model or innovation strategy. PSS address or are driven by objectives such as fulfilling customer needs, environmental efficiencies, and co-production of value.

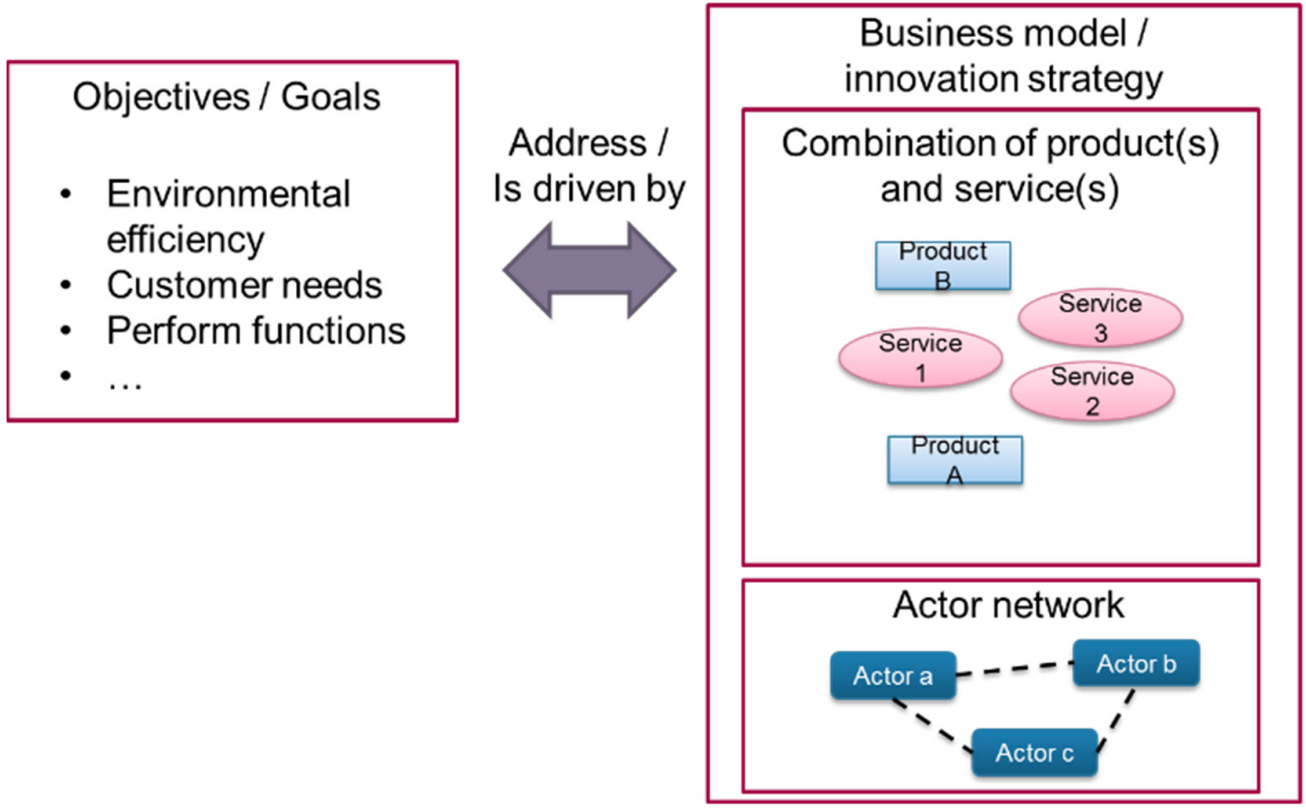

Figure 1. PSS elements prevalent in most definitions 
Some PSS definitions such as (Goedkoop et al., 1999) further include supporting infrastructure. Besides the economic meaning of "service", the service engineering PSS literature often represents services in terms of activities or processes, an outcome, and the required resources for performing the service (Bullinger et al., 2003; Elgammal et al., 2017; Hajimohammadi et al., 2017). Resources can be products, personnel, infrastructure, systems etc.

PSS and similar terms have been discussed in-depth in Velamuri et al. (2011), for example hybrid product, functional product, and integrated solution.

\subsection{System of Systems definitions and characteristics}

A number of definitions for system of systems can be found in the literature (Kotov, 1997; Lukasik, 1998; Pei, 1998; Carlock and Fenton, 2001; Sage and Cuppan, 2001; Jamshidi, 2005; Maier and Rechtin, 2006; Bjelkemyr et al., 2009). Some definitions are domain-specific, such as for a defence context (Manthorpe, 1996; Pei, 1998) or enterprise systems engineering (Carlock and Fenton, 2001). In the following, we focus on definitions that are generic and applicable to a variety of contexts. According to these definitions, a system of systems consists of a set of systems. The definitions differ in the characteristics they ascribe to this set of systems. Maier (1996) ascribes operational and managerial independence as key characteristics. Additional characteristics are introduced by (Jamshidi, 2005): geographic distribution, emergent behaviour, and evolutionary development. Another set of characteristics is introduced by Baldwin et al. (2015), Boardman and Sauser (2006): autonomy, belonging, connectivity, diversity, emergence. According to Bjelkemyr et al. (2009) SoS exhibit evolutionary behaviour, self-organization, heterogeneity, emergent behaviour, and can be interpreted as small-world and scale free networks. Other important characteristics of SoS are that capabilities and service-oriented principles play an important role in the composition of SoS (Gomes et al., 2015). Kinder et al. (2012) present different SoS dimensions that are intended to help define the system of interest: component systems, SoS classification, interactions, nature of relationships, lifecycle, variability, functions, systems owners and operations, concept of operations / use / employment. Bianchi et al. (2015) present a literature review of SoS quality attributes. They conclude that existing existing quality attributes are insufficient to address their interdependencies due to the dynamic nature of SoS.

\subsection{Towards a definition and conceptual model for PSS-SoS}

In the following, we will first compare similarity and differences of the constituent elements and characteristics of PSS and SoS. Furthermore, we present a tentative definition and conceptual model for PSS-SoS. Some PSS definitions can encompass SoS such as aforementioned in (Estrada et al., 2017). Regarding a PSS's constituent elements, most definitions agree on a set of products and services. Some definitions such as Goedkoop et al. (1999) and Mont (2002) further include a network (of actors) and an infrastructure. From a SoS perspective, at least products, infrastructure, and networks can be considered as constituent systems. Whether or not services are systems depends on how widely or narrowly the notion of system is defined and whether or not it encompasses a set of activities. As not all sets of systems are SoS, similarly, not all PSS that comprise a set of product(s), service(s), infrastructure(s), and network(s) are SoS. They have to satisfy a number of additional conditions.

In the following, we argue that most of the PSS and SoS characteristics are complementary. The PSS definitions compiled in Boehm and Thomas (2013) stress characteristics such as value generation, customer utility, fulfilling user needs, environmental benefits, etc. that are rather ends. By contrast, SoS characteristics are less focused on the ends but on its constituent elements. For example, operational and managerial independence are characteristics of a SoS's constituent systems and do not have their PSS counterpart. The same seems to hold for the additional SoS characteristics from Jamshidi (2005), geographic distribution, emergence, and evolutionary development. Baldwin et al., (2015) Boardman and Sauser's (2006) five characteristics autonomy, belonging, connectivity, diversity, emergence also do not seem to have counterparts in PSS definitions.

However, at least one PSS characteristic seems to have a counterpart in SoS definitions. Goedkoop et al. (1999) ascribes to a PSS that it "continuously strives to be competitive, satisfy customer needs, and 
have a lower environmental impact than traditional business models." This characteristic seems to have its counterpart in the "evolutionary development" characteristic from Jamshidi (2005) and "evolutionary behavior" from Bjelkemyr et al. (2009). This PSS characteristic stresses the continuous development of PSS via reconfiguration etc., induced by the interaction with the client.

To conclude, it seems that most characteristics of SoS are complementary to PSS characteristics. While PSS characteristics such as customer satisfaction, value creation, etc. are in general ends-oriented, i.e. they go beyond the perimeter of the PSS. SoS characteristics such as operational and managerial independence are means-oriented and stay within the perimeter of the SoS.

Existing publications that jointly deal with PSS and SoS rather briefly mention the SoS aspect without taking its specific characteristics into account. For example, Bankole et al. (2012), Bertoni, (2013), Erkoyuncu et al., (2011) mention system of systems such as in the context of operations (Bankole et al., 2012), cyber-physical systems (Bertoni, 2013), business collaboration (Bertoni et al., 2011), and as a case study (Erkoyuncu et al., 2011). (Püschel et al., 2016) explores the relationship between the Internet of Things with various concepts, including hybrid products and system of systems.

A different picture presents itself for service systems and service engineering. Most publications in this area deal with SoS from an enterprise system perspective. For example, Tien $(2009,2008)$, Tien and Goldschmidt-Clermont (2009) focus on the characteristic of value co-creation in services, where the provider and customer entities are considered as systems that interact. These entities comprise people, processes, and products. For example, (Tien and Goldschmidt-Clermont, 2009) view the healthcare system from this perspective. (Golinelli et al., 2015) and (Mora et al., 2011) similarly see a firm forming a SoS via collaborating with other firms, thereby co-creating value. The literature on enterprise systems engineering seems to rather focus on a single firm as a SoS. For example, Sitton and Reich (2015) and Carlock and Fenton (2001) seek to integrate component systems within a firm.

Given the complementary characteristics of PSS and SoS, we can construct a minimal definition of PSSSoS that combines the essence of PSS and SoS definitions:

A PSS-SoS is a set of products, services, infrastructures, and networks where its constituent elements exhibit operational and managerial independence.

More specifically:

- At least two actors manage / operate the constituent products and services, where one actor contributes in one or several of the following ways:

- One actor manages / operates a product, service, PSS, or infrastructure

- One actor manages multiple products, services, PSS, or infrastructures

- Actors jointly manage a product, service, PSS, or infrastructure

- The PSS-SoS consists of either of the following product / service combinations:

- One product and multiple services

- Multiple products that take part in the delivery of a service

- Multiple products and their services are combined to deliver a service

These characteristics reflect the managerial and operational independence criteria from Maier (1996). Additional SoS characteristics can be added. The main difference to SoS in general is that specifically the service dimension adds another layer of complexity to a PSS-SoS. Individual services can be combined in new ways during design-time and / or run-time, such is the case for Service-Oriented Architecture (SOA) (Erl, 2005; Russell et al., 2008; Vrba et al., 2014).

Regarding specific PSS types such as in Tukker (2004), PSS-SoS may include one or more PSS types. For example, a multi-modal transportation PSS-SoS may include a tram (result-oriented PSS) and a bicycle lending service (use-oriented PSS).

Figure 2 shows an example conceptual model for PSS-SoS with a set of products and services that are operated / managed by a network of actors. Shifting system boundaries during its operation can also result in an added complexity. 


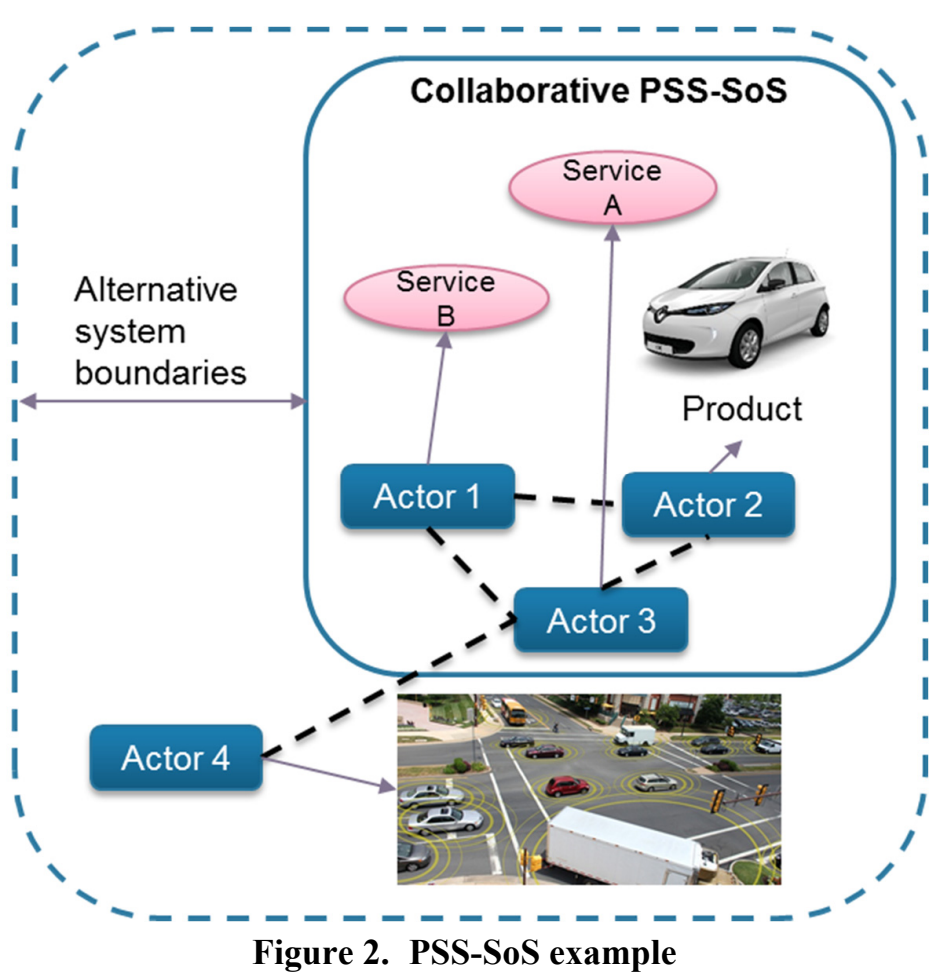

\section{PSS design methods, processes, and frameworks}

In the following, a variety of PSS design methods, processes, and frameworks are presented and their contribution to a PSS-SoS design methodology identified. The main difference between the product development and service engineering literature is that PSS design methodologies take dependencies and interactions between product and service development into account.

We screened the literature with respect to the following criteria that follow from specific PSS-SoS characteristics:

- Individual PSS and / or products and services are combined to form a PSS-SoS. Hence, the PSS design methodology should consider the recombination of PSS and / or products and services.

- The PSS design methodology takes life cycle off-sets into account, i.e. products and services are not developed at the same time or entire PSS are not developed in parallel. Rather, new services, products, and PSS are integrated into existing services, products, and PSS.

- Collaboration between actors / stakeholders that goes beyond a supplier - client, service provider - client relationship is considered.

- PSS-specific aspects such as the supporting networks and infrastructure are taken into account.

- Actors along with their roles (management, operation) can be assigned to the respective PSS-SoS elements.

The publication was retained in case it satisfies one or more of these criteria. A PSS-SoS design methodology would need to address all these characteristics.

Although not immediately applicable to the PSS-SoS case, a modular approach can likely be adapted to represent the recombination of products / services / PSS / infrastructure. Aurich et al. (2006) propose a modular product and service design process where several product and service development processes can be integrated. Such a modular design process could be extrapolated to the PSS-SoS case for combining services, products, and PSS. The proposed approach seems to be rather applicable to productoriented PSS. Kim et al. (2015) developed a service-oriented PSS development process. The PSS is developed and operated collaboratively via the service provider and product partner. Service design and product design proceed in parallel. The service provider not only designs the service but is responsible for its integration with the product, infrastructure, and actor network. Aurich et al. (2009), Wang et al. 
(2011) and Li et al. (2012) develop three different processes for modular PSS design, where products and services as well as the product life cycle (PLC) can be modular. Aurich et al. (2009) introduce a modular approach to combining services with products over the product's life cycle. Wang et al. (2011) propose a PSS design methodology for modular PSS that can be configured for different customer segments. They take collaboration between the developer, product supplier, product/service portfolio management, PSS provider, manufacturer, and customer into account. Li et al. (2012) propose to develop the service modular structure and the product modular in parallel.

Several PSS design methodologies take collaboration between actors / stakeholders into account. Morelli (2006) present a PSS development approach that takes the co-production of the final result by an actor network into account. They use interaction maps for representing actor relationships and the IDEF0 diagram for the functional aspects of the PSS. The PSS Board by Lim et al. (2012) provides a matrix for representing relationships between customer activities, services, products, infrastructure, and partners. A car-sharing company example is presented. (Van Halen et al., 2005) present PSS design methodology which includes a PSS stakeholder map for identifying stakeholders and their relationships. Geum and Park (2011) present a product-service blueprinting approach that includes ownership transfer and actor transfer that go beyond customer and provider relationships. The framework for designing and delivering value bundles presented by Becker et al. (2010) considers collaboration between the service company and manufacturing company during the design phase and the co-creation of the value bundle with the customer. Klein (2007), Scheer et al., (2006) propose a model-based framework for modelling PSS. The framework takes the organizational aspect into account via allocating organisational units to service or product development functions. Within the product-service engineering literature, Sakao et al. (2009) introduce different actor roles such as provider, intermediate agent, and receiver into their PSS flow and scope model, which allows for the representation of collaboration between actors. Although not explicitly mentioned, their approach should be allow for an allocation of products and infrastructures to services. Hara et al. (2009) use Service Blueprinting with the Business Process Modelling Notation (BPMN) for modelling product behaviour and service activities. Their running example is rather limited to individuals providing services to customers (motorman on a tramway). However, the modelling approach and notation could be adapted to the PSS-SoS case. Durugbo (2014) gives an overview of the different dimensions that influence co-design for industrial PSS. The first aspect relates to sets of requirements that are life-cycle, partnership and technical in nature. The relationship between collaboration with partners and the PSS design process is explored.

Pezzotta et al. (2012) introduce the WinWin Spiral Model for PSS Engineering. It allows for a continuous development of the PSS throughout its life-cycle and allows for accommodating life-cycle off-sets of constituent product and service elements. It also reflects value co-creation with the customer that lead to a redesign of the PSS. Details about the PSS architecture are left out and the focus is on the overall life-cycle (beginning-of-life, mid-of-life, end-of-life).

The Multilevel Design Model by Joore and Brezet (2015) represents four levels, starting with the Societal System, Socio-technical System, Product-Service System and Product-Technology System. The socio-technical system level resembles a SoS with technical and organizational elements. Nevertheless, the model stays rather vague with respect to the concrete representation of elements for each of the levels and design phases.

Other design methodologies address two or more characteristics of PSS-SoS. Kim et al. (2011a), Kim et al., (2011b) introduce a comprehensive PSS design methodology that addresses at least two aspects relevant for PSS-SoS. First, they allow for a mapping of stakeholders to product and service elements. Furthermore, their approach includes an allocation of service elements to product elements, which permits a flexible reconfiguration of product - service combinations. However, the case studies to which this process was applied has a much lower complexity. Song et al. (2015) developed a PSS innovation management framework that adds the business model design dimension to what they call strategy level. Stakeholders participate in collaborative PSS development. Furthermore, multi-stakeholder collaboration during operation of the PSS is represented as a value network. Although the case study focuses on a beverage vending machine, the overall PSS resembles a PSS-SoS with stakeholder operating distinct services and products. 
Table 1 shows which PSS design methods, processes, and frameworks address which PSS-SoS characteristics. Few approaches address more than two characteristics and none addresses all. Among the ones that address more than two characteristics are Sakao et al. (2009), Morelli (2006), Song et al. (2015), Geum and Park (2011), and Lim et al. (2012). These five approaches are rather focused on results-oriented PSS.

Table 1. PSS design methods, processes, and frameworks and which PSS-SoS characteristics they address

\begin{tabular}{|l|l|l|l|l|l|}
\hline & $\begin{array}{l}\text { Configurati } \\
\text { on of PSS, } \\
\text { product, } \\
\text { service }\end{array}$ & $\begin{array}{l}\text { Life-cycle } \\
\text { off-sets }\end{array}$ & $\begin{array}{l}\text { Collaboration } \\
\text { between } \\
\text { actors }\end{array}$ & $\begin{array}{l}\text { Supporting } \\
\text { network, } \\
\text { infrastructure }\end{array}$ & $\begin{array}{l}\text { Actor } \\
\text { roles }\end{array}$ \\
\hline (Aurich et al., 2006) & $\mathrm{X}$ & & & & \\
\hline (Kim et al., 2015) & & & $\mathrm{X}$ & & $\mathrm{X}$ \\
\hline (Aurich et al., 2009) & $\mathrm{X}$ & $\mathrm{X}$ & & & \\
\hline (Wang et al., 2011) & $\mathrm{X}$ & & & & \\
\hline (Li et al., 2012) & $\mathrm{X}$ & & & & $\mathrm{X}$ \\
\hline (Morelli, 2006) & $\mathrm{X}$ & & $\mathrm{X}$ & $\mathrm{X}$ & $\mathrm{X}$ \\
\hline (Lim et al., 2012) & $\mathrm{X}$ & & $\mathrm{X}$ & $\mathrm{X}$ & \\
\hline (Van Halen et al., 2005) & & & $\mathrm{X}$ & & \\
\hline (Becker et al., 2010) & & & $\mathrm{X}$ & & $\mathrm{X}$ \\
\hline $\begin{array}{l}\text { (Scheer et al., 2006; } \\
\text { Klein, 2007) }\end{array}$ & & & $\mathrm{X}$ & & \\
\hline (Sakao et al., 2009) & $\mathrm{X}$ & & $\mathrm{X}$ & $\mathrm{X}$ & $\mathrm{X}$ \\
\hline (Hara et al., 2009) & $\mathrm{X}$ & & $\mathrm{X}$ & & $\mathrm{X}$ \\
\hline (Kim et al., 2011) & $\mathrm{X}$ & & $\mathrm{X}$ & & $\mathrm{X}$ \\
\hline (Pezzotta et al., 2012) & & $\mathrm{X}$ & & & \\
\hline (Geum and Park, 2011) & $\mathrm{X}$ & & $\mathrm{X}$ & $\mathrm{X}$ & \\
\hline (Durugbo, 2014) & & $\mathrm{X}$ & $\mathrm{X}$ & & $\mathrm{X}$ \\
\hline (Song and Sakao, 2016) & $\mathrm{X}$ & & $\mathrm{X}$ & $\mathrm{X}$ & \\
\hline (Joore and Brezet, 2015) & & & & & \\
\hline
\end{tabular}

\section{SoS design methodologies}

With few exceptions, existing SoS design methodologies do not take PSS explicitly into consideration. These methodologies usually start with a given architecture or a predefined design space. For example, Eusgeld et al. (2011), Kargarian et al. (2016), Thacker et al. (2017) start from an existing energy infrastructure architecture and analyse its resilience. DeLaurentis (2005) and Shah et al. (2012) focus on the evaluation of SoS transportation architectures, where the architecture alternatives are already given. These architectures can be interpreted as result-oriented PSS for transporting goods or passengers from a point A to B. A shortcoming of these approaches seems that they are limited to the evaluation of SoS rather than their synthesis.

The SoS-oriented service engineering literature provides frameworks rather than methodologies. We limit ourselves to frameworks that go beyond a single firm. Tien (2009), Tien and GoldschmidtClermont (2009) present a decision-making framework for system adaptation. (Golinelli et al., 2015) present a framework for value co-creation. The applicability of these frameworks seems to be limited to pure services, which would correspond to result-oriented PSS.

A more pertinent stream of literature seems to be the Service Oriented Architecture (SOA) SoS literature. SOA can be understood as an attempt to integrate processes and data across organizations via an overarching architecture (Russell et al., 2008). Russell et al. (2008) present a conceptual model for SOA in the context of military capability where services are integrated at the business, system, and computing level. In the conceptual model, people, process, products, access to technology, and 
infrastructure are considered as resources that fulfil a responsibility in delivering a capability. The conceptual model resembles those from service engineering such as Bullinger et al. (2003) but takes cross-organizational aspects into account. Besides this, although an architecture evaluation approach is presented, architecture generation is not considered. Vrba et al. (2014) apply SOA principles to smart grids, that are considered as SoS. They define a service as "a software entity which encapsulates business or control logic as well as functionalities provided by a component." The objective is to apply SOA principles to reach a flexible, interoperable, and scalable control solution for smart grids. Although SOA principles are presented, no methodology or framework is introduced.

Next, we extend our survey and take SoS design methodologies in general into consideration to create these solutions. We limit, nevertheless, our survey to approaches that focus on frameworks and methodologies that aim at the design of SoS architecture. We exclude more life cycle, process, and management-oriented approaches. With these limitations, existing SoS design methodologies seem to be only partly able to support PSS-SoS design. Chattopadhyay et al. $(2009,2008)$ present a framework and methodology for SoS tradespace exploration. Chattopadhyay et al. (2008) present quantitative criteria for evaluating the performance of SoS such as benefit cost criteria for systems to participate in the SoS. Chattopadhyay et al. (2009) and Chattopadhyay et al. (2010) introduce a SoS tradespace exploration methodology that takes new and legacy systems into consideration. The robustness of SoS architectures over different scenarios is also considered. Ricci et al. (2014) presents a SoS tradespace exploration methodology taking -ilities into account. All these publications already start with a given set of quantitative performance criteria and do not represent service-oriented aspects. Singh and Dagli (2009) present a SoS architecture design methodology using genetic algorithms and a fuzzy assessor. They apply the methodology to a smart grid design problem. The smart grid is represented in the form of actors, functions, and systems/services. This representation seems to be well-suited for PSS-SoS. However, the methodology starts where the SoS system boundary and constituent elements have already been predefined. Mokhtarpour and Stracener (2014) propose a K-means clustering approach for SoS architecture selection. Dagli et al. (2013) present a methodology for SoS architecting and analysis using an agent-based behavioural model. They take various SoS specific aspects into consideration such as criteria for individual systems to participate in the SoS. Ingram et al. (2014) present a template for SoS architecture patterns and examples such as SOA and pipes and filters. These patterns could be used in the synthesis step of PSS-SoS architectures. Hein et al. (2016) present a methodology for architecting eco-industrial park SoS, using net-present value as a criteria for individual industrial plants to take part in the a synergy. Rhodes et al. (2009) present a framework for architecting the SoS enterprise. The framework seems to be applicable to PSS-SoS with an emphasis on the actor network and infrastructure, in particular the information technology infrastructure. However, this framework would need to be complemented by a framework that focuses on the product / service aspect of the PSS-SoS.

To conclude, existing SoS design methodologies seem to be only partly applicable to PSS-SoS. The service and capability oriented frameworks and methodologies are rather focused on result-oriented PSS. Furthermore, different types of constituent PSS of a PSS-SoS are seemingly not addressed by the literature. There seems to be a gap regarding methodologies that allow for a proper definition of the system of interest and the synthesis of PSS-SoS architectures prior to the evaluation / analysis step. In addition, a promising avenue of research could be to combine SoS enterprise architecting approaches with an approach that focuses on the products and services.

\section{Research gaps}

With respect to the existing literature, the following research gaps have been identified:

PSS product / service complexity: Existing PSS publications focus mostly on low complexity products and services, e.g. bike, clothes, vending machine. Products with a higher complexity such as automobile, aerospace systems and services that require more complex infrastructure such as service platforms are seldom covered by the existing literature and not considered in the case studies. By contrast, the SoS literature deals with these types of high-complexity systems, but only few publications take the PSS aspect into account.

Collaboration: Existing PSS approaches consider collaboration between actors such as product manufacturers and service providers during the design and operations phase and value co-creation with 
the customer during the operations phase. However, few approaches allow for jointly exploring the combination of actor collaboration alternatives and product, service, and PSS alternatives. Existing SoS design approaches take services into account, such as in the form of capabilities, but seem to be limited to defence SoS or enterprise systems.

In addition, the PSS literature only partly addresses PSS-SoS characteristics. The service-oriented SoS literature addresses some of the PSS-SoS aspects but remains implicitly at the result-oriented PSS level. The enterprise SoS literature provides frameworks for representing shared resources and processes across organizations but does not provide guidance on how to map the organizational architecture with products, services, and infrastructure elements.

\section{Conclusions}

This paper has provided a comprehensive literature survey of the existing PSS literature with respect to a PSS system of systems design methodology. The existing literature can mainly contribute with respect to life cycle, business model, and socio-technical systems aspects to the development of such a methodology. The two main research gaps are: How PSS with a high complexity (system of systems) can be represented? Furthermore, although the link between PSS and business model is considered in the literature, the existing business model representations and PSS representations are not well suited for a system of systems context with multiple actors that collaborate. How can both be developed concurrently? The future work will focus on addressing these research gaps and questions.

\section{References}

Aurich, J., Fuchs, C. and Wagenknecht, C. (2006), "Life cycle oriented design of technical Product-Service Systems", Journal of Cleaner Production, Vol 14. No .17, pp. 1480-1494.

Aurich, J.C., Wolf, N., Siener, M. and Schweitzer, E. (2009), "Configuration of product-service systems", Journal of Manufacturing Technology Management, Vol 20 No. 5, pp. 591-605. https://doi.org/10.1108/17410380910961000

Baines, T., Lightfoot, H., Evans, S., Neely, A., Greenough, R. et al. (2007), "State-of-the-art in product-service systems", Proceedings of the Institution of Mechanical Engineers, Part B: Journal of Engineering Manufacture, Vol. 221 No. 10, pp. 1543-1552. https://doi.org/10.1243/09544054JEM858

Baldwin, W., Sauser, B. and Boardman, J. (2015), "Revisiting "The Meaning of Of” as a Theory for Collaborative System of Systems", IEEE Systems Journal, Vol. 11 No. 4, pp. 2215-2226. https://doi.org/10.1109/JSYST.2015.2430755

Bankole, O., Roy, R. and Shehab, E. (2012), "Product-service system affordability in defence and aerospace industries: state-of-the-art and current industrial practice", International Journal of Computer Integrated Manufacturing, Vol. 25 No. 4-5, pp. 398-416.

Becker, J., Beverungen, D.F. and Knackstedt, R. (2010), "The challenge of conceptual modeling for productservice systems: status-quo and perspectives for reference models and modeling languages", Information Systems and e-Business Management, Vol. 8 No.1, pp. 33-66. https://doi.org/10.1007/s10257-008-0108-y

Bertoni, A. (2013), "Analyzing Product-Service Systems conceptual design: The effect of color-coded 3D representation”, Design Studies, Vol. 34 No. 6, pp. 763-793. https://doi.org/10.1016/j.destud.2013.02.003

Bertoni, M., Eres, H. and Isaksson, O. (2011), "Criteria for assessing the Value of Product Service System Design Alternatives: an Aerospace Investigation”, In: Hesselbach J. and Herrmann, C. (Eds.), Functional Thinking for Value Creation, Springer Berlin Heidelberg, Berlin, Heidelberg. pp. 141-146. https://doi.org/10.1007/978-3642-19689-8_26

Bianchi, T., Santos, D.S. and Felizardo, K.R. (2015), "Quality attributes of systems-of-systems: a systematic literature review", IEEE/ACM 3rd International Workshop on Software Engineering for Systems-of-Systems (SESOS), IEEE, pp. 23-30.

Bjelkemyr, M., Semere, D. and Lindberg, B. (2009), "Definition, classification, and methodological issues of system of systems", In: Jamshidi, M. (Ed.), Systems of Systems Engineering: Principles and Applications, CRC Press, pp. 191-206.

Boardman, J. and Sauser, B. (2006), "System of Systems-the meaning of of", IEEE/SMC International Conference on System of Systems Engineering, pp. 6.

Boehm, M. and Thomas, O. (2013), "Looking beyond the rim of one's teacup: a multidisciplinary literature review of Product-Service Systems in Information Systems, Business Management, and Engineering \& Design", Journal of Cleaner Production, Vol. 51, pp. 245-260. https://doi.org/10.1016/j.jclepro.2013.01.019 
Bullinger, H., Fähnrich, K. and Meiren, T. (2003), "Service engineering - methodical development of new service products", International Journal of Production Economics, Vol. 85 No. 3, pp. 275-287.

Carlock, P.G. and Fenton, R.E. (2001), "System of Systems (SoS) enterprise systems engineering for informationintensive organizations", Systems Engineering, Vol. 4 No. 4, pp. 242-261. https://doi.org/10.1002/sys.1021

Chattopadhyay, D., Ross, A.M. and Rhodes, D.H. (2010), "Combining Attributes for Systems of Systems in MultiAttribute Tradespace Exploration”, INSIGHT, Vol. 13 No. 2, pp. 31-38. https://doi.org/10.1002/inst.201013231

Chattopadhyay, D., Ross, A.M. and Rhodes, D.H. (2009), "Demonstration of system of systems multi-attribute tradespace exploration on a multi-concept surveillance architecture", 7th Conference on Systems Engineering Research

Chattopadhyay, D., Ross, A.M. and Rhodes, D.H. (2008), “A framework for tradespace exploration of systems of systems", 6th Conference on Systems Engineering Research, Los Angeles, CA.

Chazal, Y., Toussaint, P. and Trinh, D.-H. (2017), "B4B, a System of System Development Based on Systems Engineering Processes", In: Fanmuy, G., Goubault, E., Krob, D. and Stephan, F. (Eds.), Complex Systems Design \& Management, Springer International Publishing, Cham, pp. 247-247. https://doi.org/10.1007/978-3319-49103-5 26

Dagli, C., Ergin, N., Enke, D., Gosavi, A., Qin, R. and Colombi, J. (2013), An advanced computational approach to system of systems analysis \& architecting using agent-based behavioral model, Defense Technical Information Centre.

DeLaurentis, D. (2005), "Understanding Transportation as a System-of-Systems Design Problem", 43rd AIAA Aerospace Sciences Meeting and Exhibit. American Institute of Aeronautics and Astronautics, Reston, Virigina. https://doi.org/10.2514/6.2005-123

Durugbo, C. (2014), "Strategic framework for industrial product-service co-design: findings from the microsystems industry”, International Journal of Production Research, Vol. 52 No. 10, pp. 2881-2900. https://doi.org/10.1080/00207543.2013.857054

Elgammal, A., Papazoglou, M. and Krämer, B. (2017), "Design for Customization: A New Paradigm for ProductService System Development”, Procedia CIRP, Vol. 64, pp. 345-350.

Erkoyuncu, J.A., Roy, R., Shehab, E. and Cheruvu, K. (2011), "Understanding service uncertainties in industrial product-service system cost estimation", The International Journal of Advanced Manufacturing Technology, Vol. 52 No 9-12, pp. 1223-1238. https://doi.org/10.1007/s00170-010-2767-3

Erl, T. (2005), Service-oriented architecture: concepts, technology, and design, Prentice Hall.

Estrada, A., Romero, D., Pinto, R., Pezzotta, G. and Lagorio, A. (2017), “A Cost-Engineering Method for ProductService Systems Based on Stochastic Process Modelling: Bergamo's Bike-Sharing PSS”, Procedia CIRP, Vol. 64, pp. 417-422.

Eusgeld, I., Nan, C. and Dietz, S. (2011), “"'System-of-systems" approach for interdependent critical infrastructures”, Reliability Engineering \& System Safety, Vol. 96 No. 6, pp. 679-686.

Geum, Y., Park, Y. (2011), "Designing the sustainable product-service integration: a product-service blueprint approach", Journal of Cleaner Production, Vol. 19 No. 14, pp. 1601-1614. https://doi.org/10.1016/j.jclepro.2011.05.017

Goedkoop, M.J., van Halen, C.J.G., te Riele, H.R.M. and Rommens, P.J.M. (1999), Product Service systems, Ecological and Economic Basics, Pre consultants.

Golinelli, D., Tucker, J.S., Ryan, G.W. and Wenzel, S.L. (2015), "Strategies for Obtaining Probability Samples of Homeless Youth", Field Methods, Vol. 27 No. 2, pp. 131-143. https://doi.org/10.1177/1525822X14547500

Gomes, P., Cavalcante, E., Maia, P., Batista, T. and Oliveira, K. (2015), “A systematic mapping on discovery and composition mechanisms for systems-of-systems", 41st Euromicro Conference on Software Engineering and Advanced Applications (SEAA), pp. 191-198.

Haase, R., Pigosso, D. and McAloone, T. (2017), "Product/Service-System Origins and Trajectories: A Systematic Literature Review of PSS Definitions and their Characteristics", Procedia CIRP, Vol. 64, pp. 157-162.

Hajimohammadi, A., Cavalcante, J. and Gzara, L. (2017), "Ontology for the PSS Lifecycle Management", Procedia CIRP, Vol. 64, pp. 151-156. https://doi.org/10.1016/j.procir.2017.03.016

Hara, T., Arai, T. and Shimomura, Y. (2009), "A Method to Analyze PSS from the Viewpoints of Function, Service Activity, and Product Behavior", Proceedings of the 19th CIRP Design Conference-Competitive Design, Cranfield University Press, pp. 180-185.

Hein, A., Jankovic, M., Farel, R. and Yannou, B. (2016), “A Data- and Knowledge-Driven Methodology for Generating Eco-Industrial Park Architectures", Proceedings of the ASME 2016 International Design Engineering Technical Conferences \& Computers and Information in Engineering Conference IDETC/CIE 2016.

Ingram, C., Payne, R., Perry, S., Holt, J., Hansen, F.O. and Couto, L.D. (2014), "Modelling patterns for systems of systems architectures", 8th Annual IEEE Systems Conference (SysCon), pp. 146-153. 
Jamshidi, M. (2005), Theme of the IEEE SMC 2005. [online] IEEE SMC. Available at: http://ieeesmc2005.unm.edu/

Joore, P. and Brezet, H. (2015), “A Multilevel Design Model: the mutual relationship between product-service system development and societal change processes”, Journal of Cleaner Production, Vol. 97, pp. 92-105. https://doi.org/10.1016/j.jclepro.2014.06.043

Kargarian, A., Fu, Y., Wu, H. (2016), Ch"ance-constrained system of systems based operation of power systems", IEEE Transactions on Power Systems, Vol. 35 No. 5, pp. 3404-3413.

Kim, S., Son, C., Yoon, B. and Park, Y. (2015), "Development of an Innovation Model Based on a ServiceOriented Product Service System (PSS)", Sustainability, Vol. 7 No. 11, pp. 14427-14449. https://doi.org/10.3390/su71114427

Kim, Y., Lee, S. and Koh, D. (2011), "Representing product-service systems with product and service elements," Proceedings of ICED'11 / the 18th International Conference on Engineering Design, Copenhagen, Denmark, August 15-18, 2011.

Kim, Y.S., Lee, S.W., Lee, J.-H., Han, D.M. and Lee, H.K. (2011), “Design Support Tools for Product-Servce Systems", Proceedings of ICED'11 / the 18th International Conference on Engineering Design, Copenhagen, Denmark, August 15-18, 2011.

Kinder, A., Barot, V., Henshaw, M. (2012), "System of Systems:"Defining the system of interest"”, 7th International Conference on System of Systems Engineering (SoSE).

Klein, R. (2007), Modellgestütztes Service Systems Engineering: Theorie und Technik einer systemischen Entwicklung von Dienstleistungen, Springer-Verlag.

Kotov, V. (1997), Systems of systems as communicating structures, Hewlett Packard Laboratories.

Li, H., Ji, Y., Gu, X., Qi, G. and Tang, R. (2012), "Module partition process model and method of integrated service product", Computers in Industry, Vol. 63 No. 4, pp. 298-308.

Lim, C.-H., Kim, K.-J., Hong, Y.-S. and Park, K. (2012), "PSS Board: a structured tool for product-service system process visualization", Journal of Cleaner Production, Vol. 37, pp. 42-53. https://doi.org/10.1016/j.jclepro.2012.06.006

Lovelock, C. and Gummesson, E. (2004), "Whither services marketing? In search of a new paradigm and fresh perspectives", Journal of Service Research, Vol. 7 No. 1, pp. 20-41.

Lukasik, S. (1998), "Systems, systems of systems, and the education of engineers", AI EDAM, Vol. 12 No. 1, pp. 55-60.

Mahut, F., Daaboul, J., Bricogne, M. and Eynard, B. (2017), « Product-Service Systems for servitization of the automotive industry: a literature review”, International Journal of Production Research, Vol. 55 No. 7, pp. 2102-2120. https://doi.org/10.1080/00207543.2016.1252864

Maier, M.W. and Rechtin, E. (2006), The art of systems architecting, 2nd ed., CRC Press.

Maier, M. (1996), “Architecting principles for systems-of-systems”, INCOSE International Symposium.

Manthorpe, W.H. (1996), "The emerging joint system of systems: A systems engineering challenge and opportunity for APL", Johns Hopkins APL Technical Digest, Vol. 17 No. 3, pp. 305.

Mokhtarpour, B. and Stracener, J. (2014), "Application of a clustering technique in identifying the "best" System of Systems (SoS) during development”, 2014 IEEE International Conference on Systems, Man and Cybernetics (SMC), pp. 1598-1604.

Mont, O. (2002), "Clarifying the concept of product-service system”, Journal of Cleaner Production, Vol. 10 No. 3, pp. 237-245.

Mora, M., Raisinghani, M., Gelman, O. and Sicilia, M.A. (2011), "Onto-ServSys: A Service System Ontology", In: Demirkan, H., Spohrer, J. and Krishna, V. (Dds), The Science of Service Systems. Service Science: Research and Innovations in the Service Economy, Springer, Boston, MA, pp. 151-173. https://doi.org/10.1007/978-14419-8270-4_9

Morelli, N. (2006), "Developing new product service systems (PSS): methodologies and operational tools", Journal of Cleaner Production, Vol. 14 No. 17, pp. 1495-1501. https://doi.org/10.1016/j.jclepro.2006.01.023

Pei, R. (1998), "System of Systems Integration (SoSI)-A“ SMART” Way of Acquiring Army C412WS Systems", Summer Computer Simulation Conference, Society for Computer Simulation International, pp. 574-579.

Pezzotta, G., Cavalieri, S. and Gaiardelli, P. (2012), “A spiral process model to engineer a product service system: An explorative analysis through case studies", CIRP Journal of Manufacturing Science and Technology, Vol. 5 No. 3, pp. 214-225. https://doi.org/10.1016/j.cirpj.2012.07.008

Püschel, L., Röglinger, M. and Schlott, H. (2016), "What's in a Smart Thing? Development of a Multi-layer Taxonomy", 37th International Conference on Information Systems (ICIS).

Rhodes, D.H., Ross, A.M. and Nightingale, D.J. (2009), "Architecting the system of systems enterprise: Enabling constructs and methods from the field of engineering systems", 3rd Annual IEEE Systems Conference, pp. $190-195$. 
Ricci, N., Fitzgerald, M.E., Ross, A.M. and Rhodes, D.H. (2014), “Architecting systems of systems with ilities: An overview of the SAI method", Procedia Computer Science, Vol. 28, pp. 322-331.

Russell, D., Looker, N., Liu, L. and Xu, J. (2008), "Service-oriented integration of systems for military capability", 2008 11th IEEE International Symposium on Object Oriented Real-Time Distributed Computing (ISORC), IEEE.

Sage, A.P. and Cuppan, C.D. (2001), "On the Systems Engineering and Management of Systems of Systems and Federations of Systems”, Information Knowledge Systems Management, Vol. 2 No. 4, pp. 325-345.

Sakao, T., Shimomura, Y., Sundin, E. and Comstock, M. (2009), "Modeling design objects in CAD system for service/product engineering”, Computer-Aided Design, Vol. 41 No. 3, pp. 197-213.

Scheer, A.W., Grieble, O. and Klein, R. (2006), "Modellbasiertes Dienstleistungsmanagement”, In: Bullinger, H.J. and Scheer, A.W. (Eds.), Service Engineering, Springer, Berlin, Heidelberg, pp. 19-51.

Shah, N.B., Sussman, J.M., Rhodes, D.H. and Hastings, D.E. (2012), "Influence strategies for systems of systems", 7th International Conference on System of Systems Engineering (SoSE), pp. 471-478.

Singh, A., Dagli, C.H. (2009), "Multi-objective stochastic heuristic methodology for tradespace exploration of a network centric system of systems", 3rd Annual IEEE Systems Conference.

Sitton, M. and Reich, Y. (2015), "Enterprise Systems Engineering for Better Operational Interoperability", Systems Engineering, Vol. 18 No. 6, pp. 625-638. https://doi.org/10.1002/sys.21331

Song, W. and Sakao, T. (2016), "Service conflict identification and resolution for design of product-service offerings", Computers \& Industrial Engineering, Vol. 98, pp. 91-101.

Thacker, S., Pant, R. and Hall, J.W. (2017), "System-of-systems formulation and disruption analysis for multiscale critical national infrastructures”, Reliability Engineering \& System Safety, Vol. 167, pp. 30-41.

Tien, J.M. (2009), “A System of Systems View of Services”, In: Jamshidi, M. (Ed.), System of Systems Engineering, John Wiley \& Sons, Inc., Hoboken, NJ, USA, pp. $293-316$. https://doi.org/10.1002/9780470403501.ch13

Tien, J.M. (2008), "On integration and adaptation in complex service systems", Journal of Systems Science and Systems Engineering, Vol. 17 No. 4, pp. 385-415.

Tien, J.M. and Goldschmidt-Clermont, P.J. (2009), "Healthcare: A complex service system", Journal of Systems Science and Systems Engineering, Vol. 18 No. 3, pp. 257-282.

Tukker, A. (2004), "Eight types of product-service system: eight ways to sustainability? Experiences from SusProNet", Business Strategy and the Environment, Vol. 13 No. 4, pp. 246-260. https://doi.org/10.1002/bse.414

Tukker, A. and Tischner, U. (2006), "Product-services as a research field: past, present and future. Reflections from a decade of research", Journal of Cleaner Production, Vol. 14 No. 17, pp. 1552-1556.

Van Halen, C., Vezzoli, C. and Wimmer, R. (2005), Methodology for product service system innovation: how to develop clean, clever and competitive strategies in companies, Uitgeverij Van Gorcum.

Velamuri, V.K., Neyer, A.-K. and Möslein, K.M. (2011), "Hybrid value creation: a systematic review of an evolving research area", Journal für Betriebswirtschaft, Vol. 61 No. 1, pp. 3-35. https://doi.org/10.1007/s11301-011-0070-5

Vrba, P., Mařík, V., Siano, P. and Leitão, P. (2014), “A review of agent and service-oriented concepts applied to intelligent energy systems”, IEEE Transactions on Industrial Informatics, Vol. 10 No. 3, pp. 1890-1903.

Wang, P.P., Ming, X.G., Li, D., Kong, F.B., Wang, L. and Wu, Z.Y. (2011), "Modular Development of Product Service Systems", Concurrent Engineering, Vol. 19 No. 1, pp. 85-96. https://doi.org/10.1177/1063293X11403508

Whittington, R. (2001), What is strategy-and does it matter?, Cengage Learning EMEA.

Dr.-Ing. Andreas Makoto Hein, Postdoc

CentraleSupélec, Université Paris-Saclay, Laboratoire Genie Industriel

3 Rue Joliot Curie, 91190 Gif-sur-Yvette, France

Email: andreas-makoto.hein@centralesupelec.fr 